\title{
MINES, QUARRIES AND LANDSCAPE. VISUALITY AND TRANSFORMATION
}

\author{
Carlos López JIMENO \\ Escuela Técnica Superior De Ingenieros De Minas. UPM \\ Ignacio Díez TORRIJOS \\ CERCLE Territorio, Paisaje y Arquitectura \\ Carmen Mataix GONZÁLEZ \\ ALBA Ingenieros Consultores, S.L
}

\begin{abstract}
:
In this paper a review of two basic concepts is carried out: scenery and landscape integration, proposing a new concept: "visuality", alternative to the classical "visibility" used in landscape studies related to mining activity, which explores the qualitative aspects that define the visual relationships between observer and environment. In relation to landscape integration studies, some reflections on substantive issues are made which induce certain prejudices at the time of addressing the issue of mining operations landscape integration, and some guidance and integration strategies are formulated. In the second part of the text, a new approach to the landscape integration of mines and quarries is raised, closely linked to the concept of visuality which are based on a basic goal: the re-qualification of the place, and give innovative answers to re-qualify the place and show how to catch the opportunity in the deep transformation generated by the development of mining activities. As a conclusion, a case study is presented in the last section, the landscape integration study conducted on marble exploitations Coto Pinos (Alicante, Spain), considered the largest ornamental rock quarry in Europe.
\end{abstract}

Key words: landscape, landscape integration, visuality, requalification

\section{APPROACHES TO THE CONCEPT OF LANDSCAPE}

A definition of landscape that has been widely embraced is that established by the European Landscape Convention: "Landscape is any part of the territory, as it is perceived by communities, whose nature results from the action of natural and human factors and their interrelationship". Thus, the landscape is a fact that arises from the relationship between a community and its environment. You can not understand the reality of a place without analyzing the cultural component of geographical space appropriation a given community carries out.

According to Martinez de Pison [3], landscape is the result of historical experience and can tell landscape-image from landscape-territory. The landscape-territory emerges as geographical shape and object, accumulating territorial history, and landscape-image as a created image, reservoir of looks over time, sum of experiences, practices, studies, thought, identities and art. "Visuality" of a place is the landscape-image and its territorial materialization (Fig. 1).

Despite changes in the territory, the vast majority of places still retain their character. The landscape is full of places that embody people's experience and aspirations; places that become centers of meaning, in symbols expressing thoughts, ideas and different emotions.

Back to the European Landscape Convention definition, "landscape" is an area as perceived by people, whose nature is the result of action and interaction of natural and/or human factors (Fig. 2).

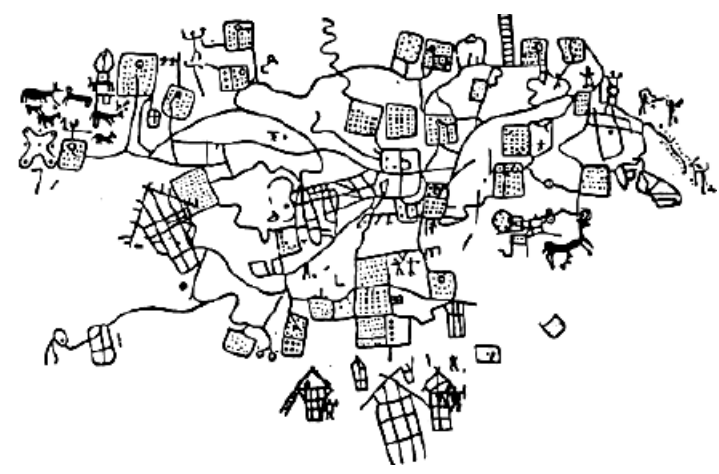

Fig. 1 Example of protho-landscape. The interpretation of physical and visual relationships of a community with its territory. This map is one of the first to represent a system of routes, it was made about 10,000 years ago in Bedolina, Val Camonica, Italy. It represents a system of everyday life connections in a Paleolithic settlement

Source: Mariano Pallotoni, Alle origini della città europea, Quasar, Roma, 1985.

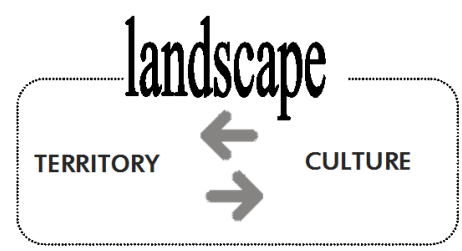

Fig. 2 Diagram showing the relationship between physical reality of a territory and our cultural representation, from which the concept of landscape is born

Source: Díez Torrijos et al, 2016 [1]. 
This definition - which comes from the agreement between the Council of Europe Member States, is not merely theoretical. Its main objective is to promote protection, management and planning of all landscapes, both natural and rural areas, such as urban and peri-urban areas, and includes not only those who might be considered outstanding, but also everyday or degraded landscapes.

Another important contribution is the recognition that landscape has an important public interest role in the cultural, ecological, environmental and social field, it constitutes a favorable resource to economic activity and its protection, management and planning can contribute to job creation. From this perspective, at the root of landscape concerns we find - without a doubt, the loss of territory environmental quality.

The disappearance of high ecological value areas, the advance of urban fabric, pollution and degradation of many places, the abandonment of agricultural activity that blurs the traces of high cultural value landscapes; the implementation of infrastructures that fragment the territory; and the dispersion of uses such as industry or mining that alter traditional patterns are factors that draw a scenario which is breeding ground for an increasingly spread concern generated by the landscape, as a continuation of an environmental awareness with a more and more important social support.

This social demand is having a major impact at the legislative level through laws that encourage to carry out public participation plans in the frame of regional planning, and particularly the recognition of attachment bonds of a community with its territory.

In this context of greater social clamor for territory nature we live in, the need to integrate landscape integration studies within the dynamics of larger territorial transformation processes arises. This is the case of mining.

\section{LANDSCAPE INTEGRATION OF MINING ACTIVITIES. REFLECTIONS.}

Landscape integration means all actions that aim to ensure the implementation of a project or proposal with the environment where it is located in a consistent manner [2]. It is an implementation process of a new activity in the territory that assumes landscape as an argument, suggestion and conditioning at all times, looking for the slightest alteration of the characteristic features of the place.

In terms of mining, practice has led on many occasions to implement the mining activity turning a blind eye to territorial and social context, and too often landscape integration actions take place after the fact, when the mining activity ceases. This causes the focus of place's value increa- sing measures taken to have a palliative nature for the negative effects such action may have caused on the environment.

That said - understanding mining as an anthropic process on the territory that will generate a transformation thereof, a key question arises: Can we establish patterns leading landscape transformations caused by this activity to situations that do not break with landscape values or cause a devaluation of the place which will have to subsequently be corrected?

The answer is clear, the objective is not restoring the nature, but integrating all the factors that make a place valuable into the evolution of nature. We must take from the outset mining activity with landscape as common theme, as argument. Landscape must be a source of suggestions and restrictions which consider extractive action as a project in the landscape, as a process of designing with nature, understanding its processes, uniqueness and essence.

Strategic planning prior to implementation of the activity - on decisions such as location of the excavation voids, location of facilities necessary for access roads extraction or design, is a key aspect in the landscape integration of mining sites and it requires meticulous environmental design.

At the sudden transformation of the territory, it is necessary to study possible ways for receptiveness of the change in the landscape and ecological mosaic regeneration. In short, re-qualification of the altered space. This increase in value can be of environmental, cultural, socialvisual and even economic nature, through the implementation of new activities.

In this understanding between activity and environment, the dialogue that must be provided with tools to improve communication between a new modifying agent and the environment arises. Somehow, the specificity of each situation must guide the approach the re-qualification of a place must follow.

In short, landscape integration solutions must direct efforts towards the requalification of the place. They must achieve a value increase of the affected space, integrating ecological, economic, social and visual values and also taking economic activity into account.

\section{Integration vs. Visibility}

Very often, the issue of landscape integration comes down to the idea of visibility, but landscape requires more than a mere spectator perspective (Fig. 3). Simplifying the visibility of an action to assess its integration into the landscape reduce integration to a mere quantitative reading, a descriptive model.
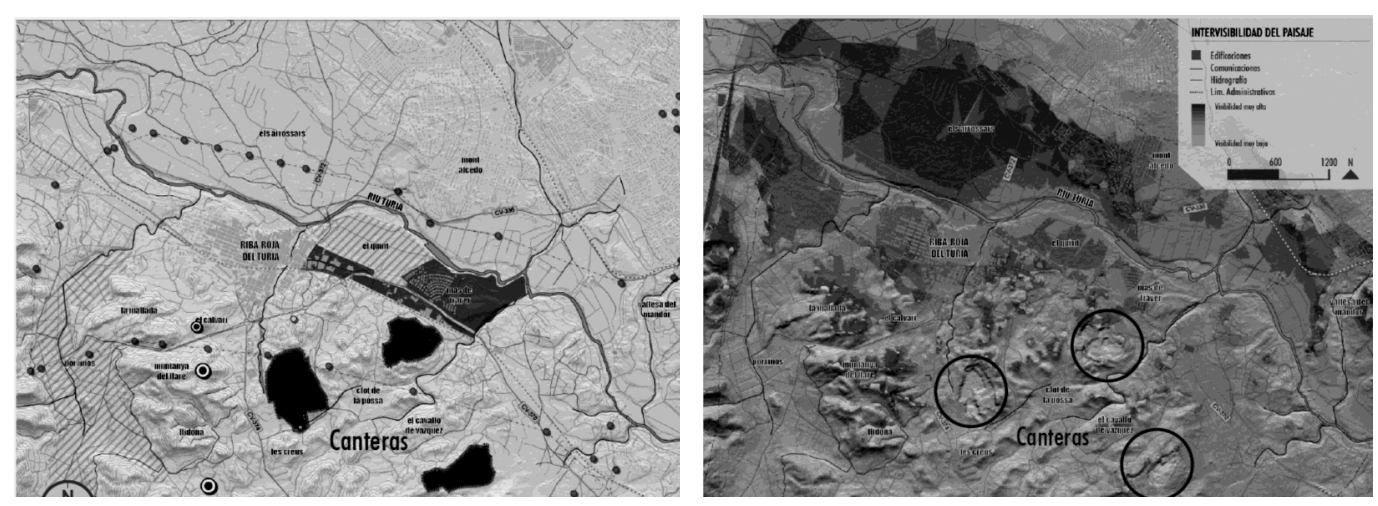

Fig. 3 Graphical representation of the spaces less valued by people (left) and landscape intervisibility map (right), what reflect the visual exposure of the territory (Ribarroja del Turia, Valencia-Spain)

Source: Diez Torrijos et al, 2016 [1]. 
It is preferable to go for qualitative and supporting models which supplement the quantitative analysis with sociocultural issues that will enrich the debate and provide intervention criteria.

In territories where cultural or social burden decreases, rational intervention models integrating environmentaleconomic variables can have more weight. However, new variables can be added to the design process that add value to the site such as those aesthetic or visual, in the style of the land-art movement which provide identity to a remote place through a purely aesthetic or formal gesture

Instead of landscape visibility, the concept of "visuality" is introduced, which incorporates the former. The "visuality" study of a landscape explores the qualitative aspects that define the visual relationships between observer and environment. "Visuality" characterizes a landscape, a displayed territory, the spatial relationships that occur more frequently between a community and its environment.

Integration - degrees of freedom - program vs. landscape logic

The concept of landscape integration integrates two components: the activity and the landscape where it is located. The variability of situations is huge and we must reflect on these issues.

The territory holds degrees of freedom inherent to their physiognomy and other derivatives of the restrictions imposed therein. In this sense, it is important to represent environmental-legal restrictions of a territory before carrying out an action. These restrictions are specific to a place and a particular time (Fig. 4).

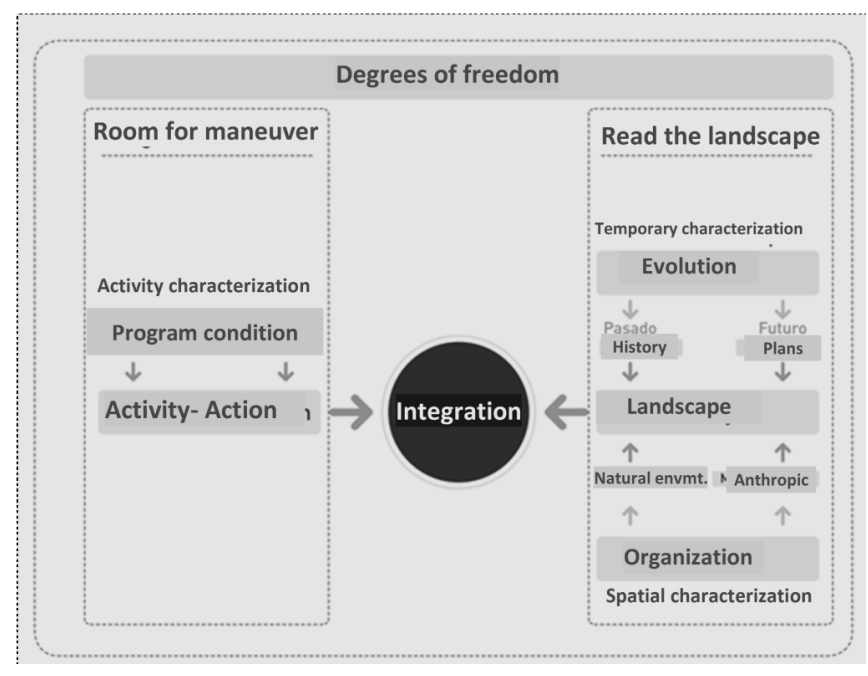

Fig. 4 Landscape integration scheme

Source: Díez Torrijos et al, 2016 [1].

Likewise, the program of the activity to be implemented plays a crucial role in the dialogue between action and support. In the case of mining, the type of extraction to be carried out implies degrees of freedom or other kind, and we need to know the room for maneuver to be able to adapt. In this regard, knowing aspects such as production processes, implementation stages, specificity of the site (dip, depth, etc.) or extraction and storage systems can provide simple tips at the time of operating in the intermediate ground that can better link an action to a certain landscape.

\section{Intensity and transformation}

The intensity of the action reduces the room for maneuver in landscape integration processes, especially those that lead to measures to protect the pre-existing landscape. In larger actions, mitigation mechanisms become more important.

Riotinto mines are an example of imposition of a new pattern on the landscape. The entity of the transformation annul any trace of pre-existence. A new landscape emerges, a scenario with no reference. The mining site is an opportunity to promote a "visuality" that recovers the historical memory and re-qualify this place, Fig. 5.

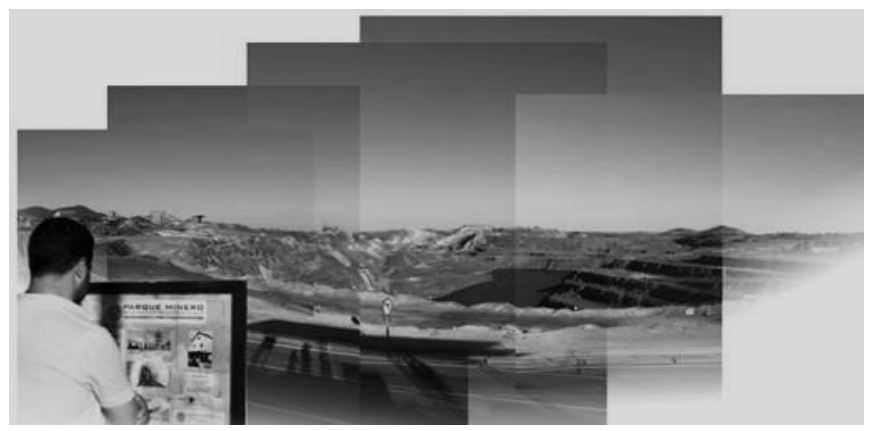

Fig. 5 Park mining of Riotinto mine

Source: Díez Torrijos et al, 2016 [1].

The intensity of the intervention is a key factor and larger actions must be decided within a strategic spatial planning process, working a priori the mutation of the landscape and providing integration criteria during their execution. Massive and large extraction activities have effects beyond their immediate environments, and their analysis often escape from landscape integration works, although these provide criteria for process improvement as well, Fig. 6.

\section{Integration strategies: the wound in the landscape}

Visuality analysis of a landscape can provide conclusions about the path to follow when dealing with a mining site integrating-regenerating action. Two ways to face the intervention to increase landscape value can be set in principle, among which there are plenty of intermediate situations.

The two ways of approaching the problem can be summarized as "heal the wound" or "assume the wound and emphasize its value." These two trends lead to ways to undertake the project, involving different strategies, Fig. 7.

The gesture of rehabilitating a space in order to "heal the scar" leads to acceptance of that landscape as a place devalued after the alteration and therefore re-qualification is conducted through mechanisms of concealment, mimicry, assimilation of the environment or re-naturalization processes. The deletion of traces caused by human action has an approach to increase the place value assuming the environmental variable as the key factor of the action. However, it is the busiest path in the integration of mines and quarries due to the dispersion of this activity in the territory, in places where "visuality" displays perceptive gaps, hidden spaces not learnt by the community.

However, strategies have to respond to more complex situations in territories of rich and complex "visuality", full of cultural and historical references. These are isolated cases, but tend to result in situations showing the debate remains open, away from dogmatism which assume a universality in how to deal with the landscape. 


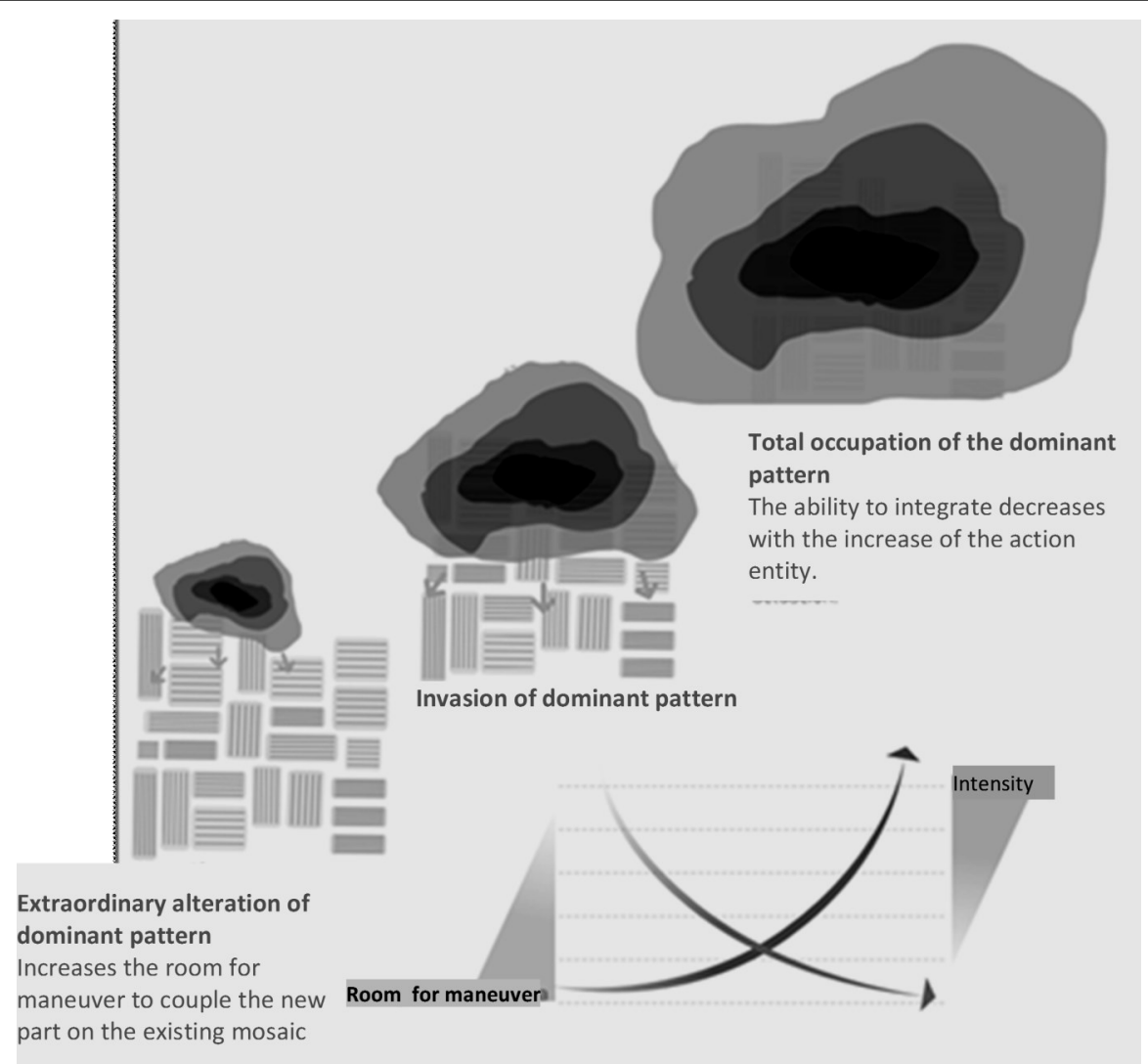

Fig. 6 Intensity vs. integration

Source: Díez Torrijos et al, 2016 [1].

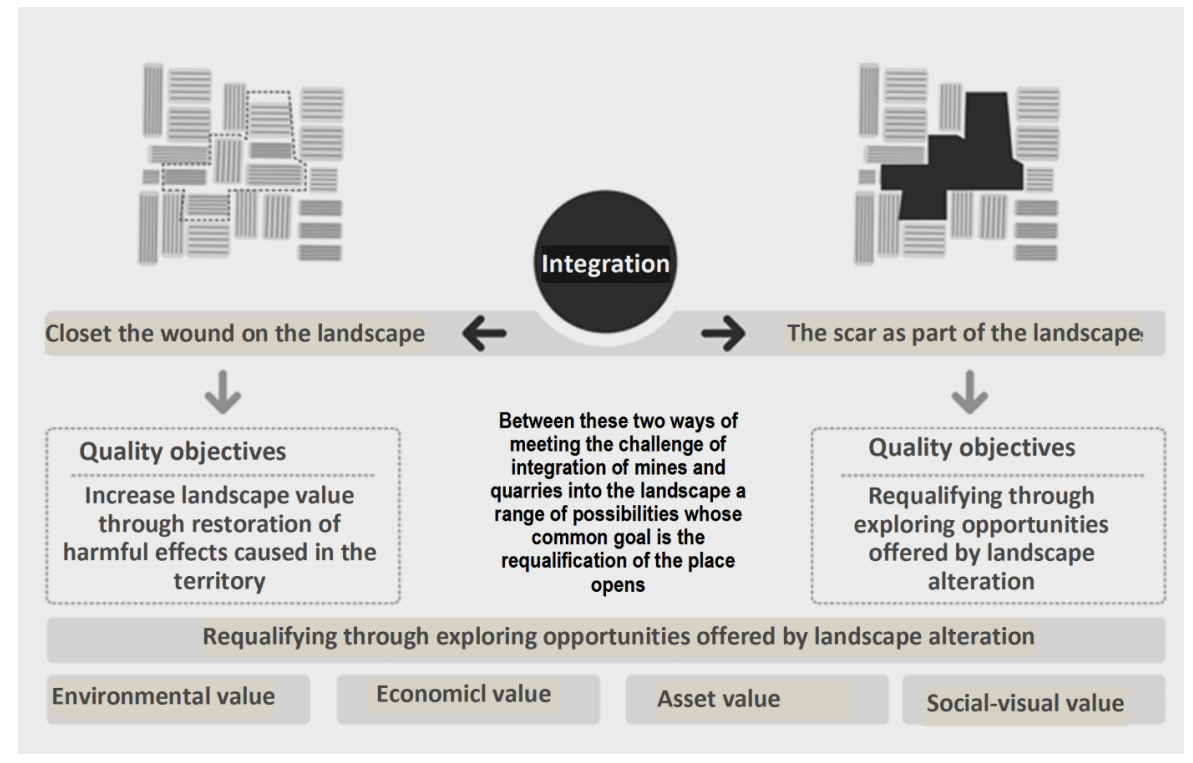

Fig. 7 Theoretical scheme to approach landscape integration measures and possibilities Source: Díez Torrijos et al, 2016 [1].

On the opposite pole of this conception, the way of acting on the landscape is "assuming the scar" generated by the activity as a cultural trail of a community, sometimes mandatory due to impossibility to return to point 0 , other times becoming an opportunity for the re-qualification of a place.

In this sense, the integration of public use in old quarry promotes apprehension about "the wound" and generates new uses. These dynamics cause a "visuality" on these spaces which assumes contemporary aesthetic categories, assuming the current mixing of landscapes.
The integration of mining into the landscape is similar to a design process in which the ultimate goal is to re-qualify the place, assuming the restrictions these impose and maximizing their potential. Whether it is a priori work, before starting the activity or when the extraction activity is completed and begins the abandonment phase, strategies to address the process of integration of a new piece in the territorial mosaic must be established.

Between these two extremes there are experiences that show the diversity of approaches which assume the complexity of the challenge posed by new transformations in the landscape. This work intends to shed light on integra- 
01 Imitation

02

Concealment

\section{Closing the wound} on the landscape

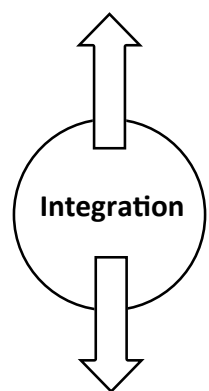

The scar as part of

the landscape
04

Contextualization

05

Harrmonization

06

Singularization

03 Fusion

07

Positive „visuality”
Built facilities acquire environmental indentity models of the rural backgroud such as texture material, shape and on transpositions in forms thereof. The best examples are found in primitive architective, in ground constructions, and little evolved vernacular constructions

Resource that tries to partially or fully conceal the view of certain elements, those consider undesirable or of some impact. Actions like plant screens, structures, etc.

The shape is based on the acquisition of the geometric model of the natural, in which contrast that built works as a rationalizing element. For example, Greek and Roman theaters carved into the hillsides, or castled settlements in heigh whose wall perimeter is comparable to a geometrization of the terrain relief

It seeks countinuity between the existing elements and new elements of the project that allow to establish logical relations between the two types (types, volumes, chromaticism, escales, ect.)

Potentiation of natural components (soil, vegetation, water, ect.) and/or existing patterns. It seeks to recover the vision of natural or camouflaing the place, knowing that it will never be possible to return to the original conditions.

It establish new relations between the action and landscape elements. Contrast is often used as an expressive resource of the project. This strategy must be used in a very controlled manner and in very specific cases

The cultural assimilation of a landscape requires increasing the value of space by integrating public use as a vector generator of a new visuality allowing a positive reading of the landscape mutation

The introduction of new uses in an old mine involves economic and socia appreciation of the landscape. From facilities to service centers (tourism, sports or other)through waste treatment sites or even as spaces for cultural

Source: Díez Torrijos et al, 2016 [1].

tion mechanisms that address value increase strategies for a place, taking into account environmental, social-visual, cultural, and economic aspects.

Between closing the wound or assuming the scar as part of the landscape, a range of possibilities that must be explored in order to find those strategies that improve cultural, social, economic, environmental and visual conditions appear. Generally it is difficult to assume a comprehensive value increase strategy of all these values, and we have to weigh the need to prioritize one or the other depending on the specificity of each situation, in relation to the "genius loci" and its singularities.

The Table 1 lists a number of guidelines that can summarize the list of basic strategies that can be assumed. These can be simultaneously implemented in a landscape integration process where the complexity of the project requires it.

Imitation and concealment strategies are more present in the scope of wanting to "close the wound" or at least disguise it, strategies such as harmonization or merger are guidelines that require a higher level in the complexity of dialogue between activity and context.

Moreover, guidelines as singularization or cultural assimilation appeal to the emphasis of the scar value on the landscape. A fact that is the result of historical development in many cases, and instead of being deleted must be explained in order to foster a positive visuality towards it.

\section{A NEW VIEW OF MINING AREAS INTEGRATION}

The transforming capacity of the mining activity - very significantly increased in recent decades, has resulted in the alteration of the environment in a way that had not taken place previously. This landscape mutation leads to alterations in physiognomy which in essence are the starting point to devise alternative futures.

Given the new unprecedented scenarios created, original project answers are emerging that provide another perspective on the problem and similarly there are experiences that show how to capture the opportunity in devastation.

The impossibility to return to point 0 , the lack of resources to establish a program of power similar to changes resulting from mining activities or the need to adapt to a situation reversal period which is far from immediacy make necessary approaches that assume these conditions and guide the changes on landscape towards situations which improve the situation as far as possible from an environmental, cultural, scenic and economic point of view.

\section{The difficulty of returning to point 0}

Sometimes the devastation is so intense that a return to a situation previous to the extraction of materials is taken as impossible. In fact, it is common to find restoration processes that - assuming this condition, choose to integrate the "wound into the landscape" in the design process.

An example of this approach is the restoration of Croscat volcano, in the Natural Park of Garrotxa volcanic area 
(Girona, Spain). The volcanic cone has a horseshoe shape and its northeastern flank was quarried for volcanic gravel until the early 1990s, exposing the internal structure of the cone from top to bottom. At Croscat volcano was chosen to give value to the "wound". The upgrading of the space had as leitmotiv the opportunity to show a volcano from the inside, thus recreating the aridity environment of volcanic landscapes, Fig. 8.

Lack of resources. "Low Cost" interventions.

Action strategies are often constrained by the lack of economic and financial resources to address the space requalification. Efficiency in resource management is of vital importance. There are many examples where the redefining of a high aesthetic quality space and perfectly integrated into the landscape is achieved.

The old marble quarries of Dionysus (Greece) were converted into environmental sculpture and open museum of traditional quarrying arts. Most stone stockpiles were left as they were at the closing of the quarry, and can be visited along a carved path. Part of the neglected facilities was also consolidated for visitor's use and the quarried stone was taken advantage of, using dry-wall techniques, Fig. 9.

\section{Time-Tempo. Stages}

The scale of the impact often reaches such dimensions that strategies must be organized in very long periods of time. The sequence of actions that includes restoration or integration shall adapt to the "tempo" of the surrounding environment, natural and anthropogenic factors which will continue to act in the place. This is, therefore, to "manage" the change because landscape is dynamic.

Recycling of spaces and giving new life to spaces degraded by the extraction of materials is not new. Back in the Renaissance we find cases such as Boboli Gardens in Florence (Fig. 10) or the romantic recovery of Buttes Chaumont in Paris, which use a unique topography and a scenography to reverse the situation and enhance the place.

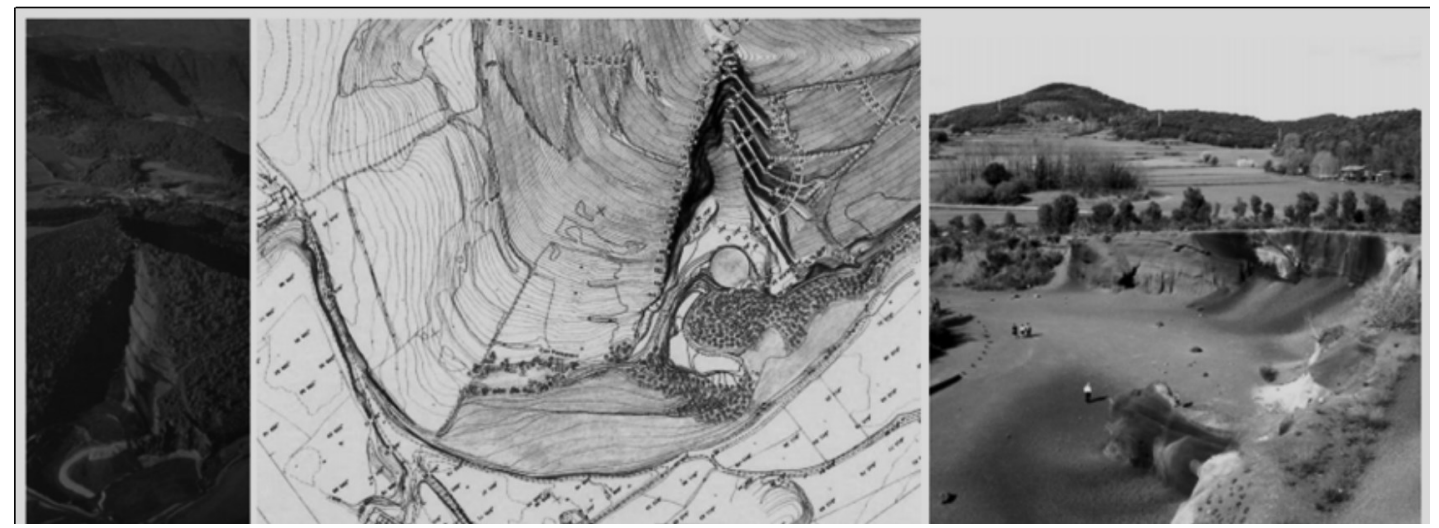

Fig. 8 Croscat volcano reclamation, in the Natural Park of Garrotxa volcanic area (Girona, Spain) Source: Projecte de Restauració del volcà Croscat. ASPECTE Paisatge. Inc. in Díez Torrijos et al, 2016 [1].
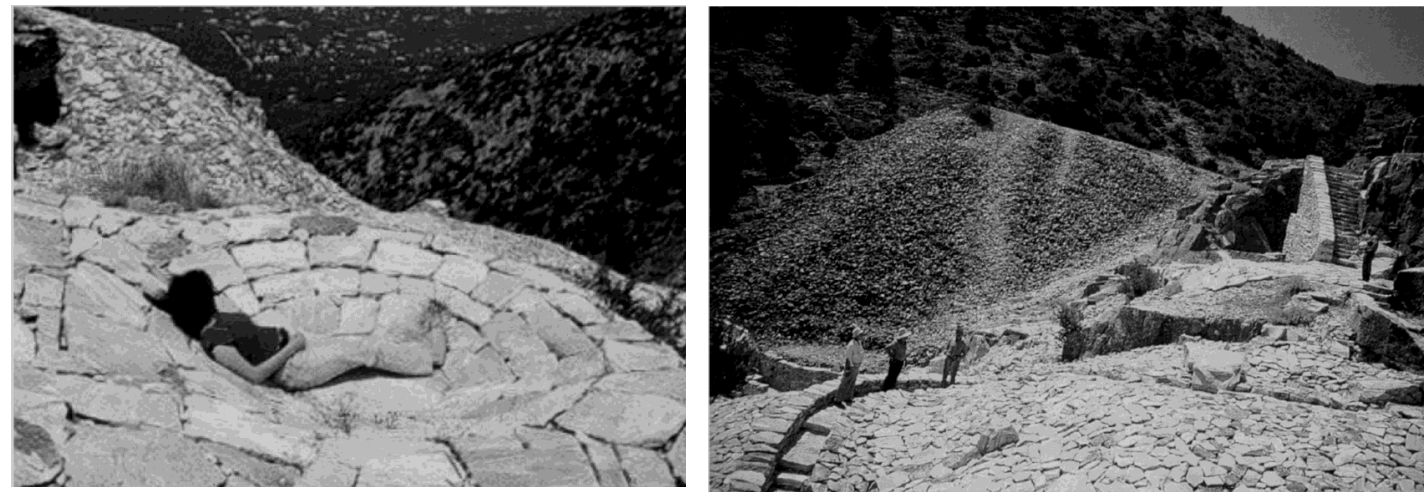

Fig. 9 Dionysus quarries reclamation

Source: http://arquitecturaecologia.blogspot.com.es. ETSAM Inc. in Díez Torrijos et al, 2016 [1].

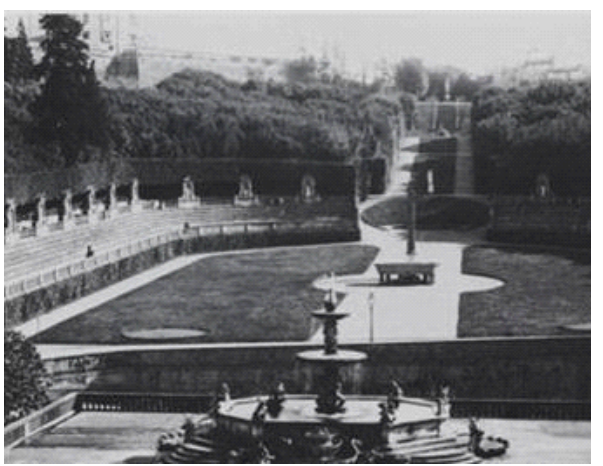

Fig. 10 Boboli Gardens Amphitheatre, viewed from the Palazzo Pitti (Florence, Italy). Amphitheater built taking advantage of an old quarry Source: Photo Ricardo André Frantz. 


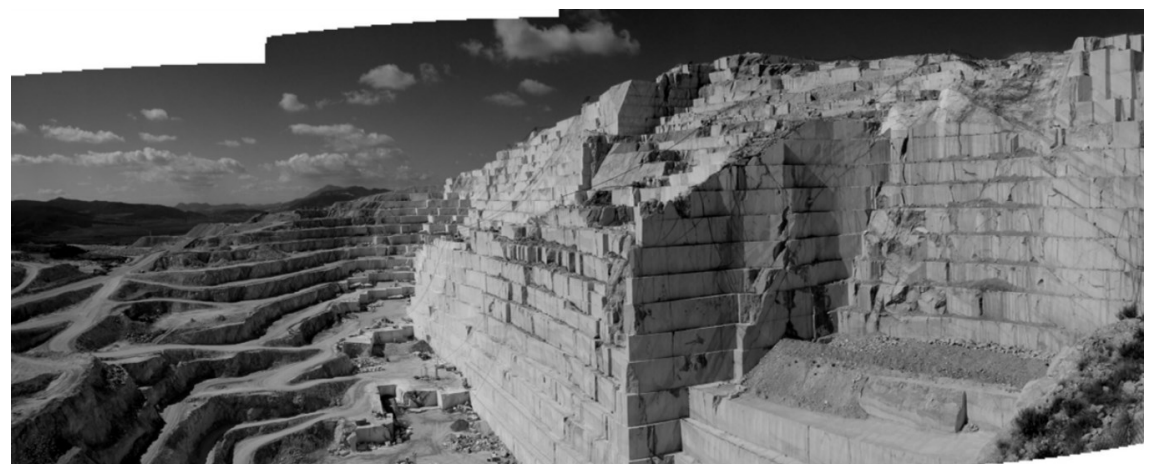

Fig. 11 Cream marble quarries in Monte Coto (Alicante, Spain)

Source: Photo Bruno Almela.

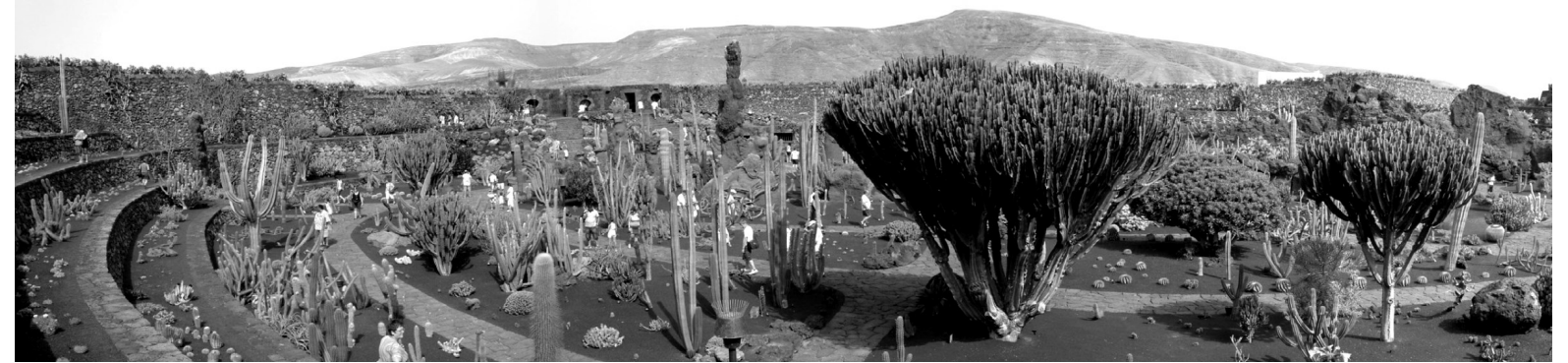

Fig. 12 Old quarry recovered by César Manrique to create "The cactus garden".

Source: Photo Alchemist-hp.

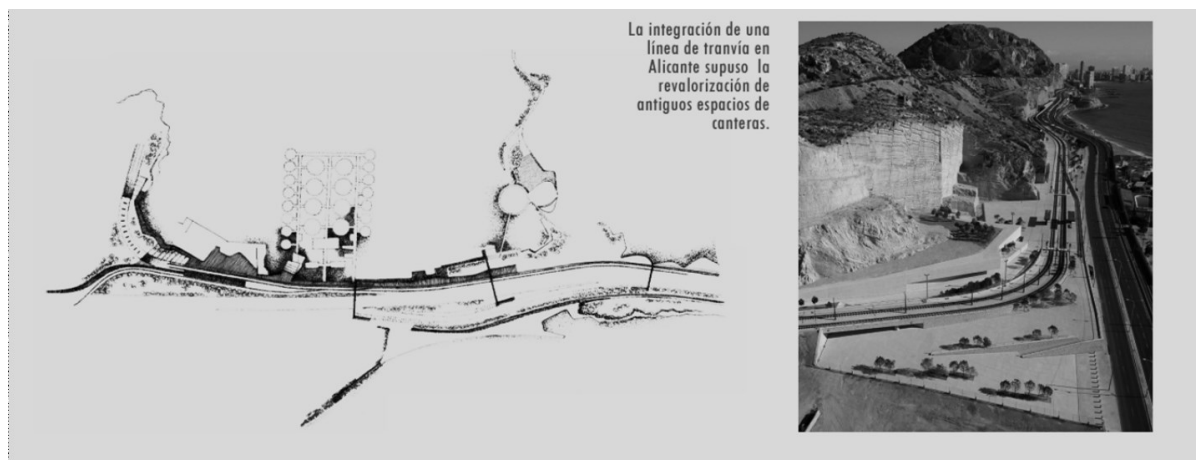

Fig. 13 The integration of a tram line in Alicante meant the value increase of old quarries spaces Source: Díez Torrijos et al, 2016 [1]. Photo: Duccio Malagamba (Arquitectura Viva n 136).
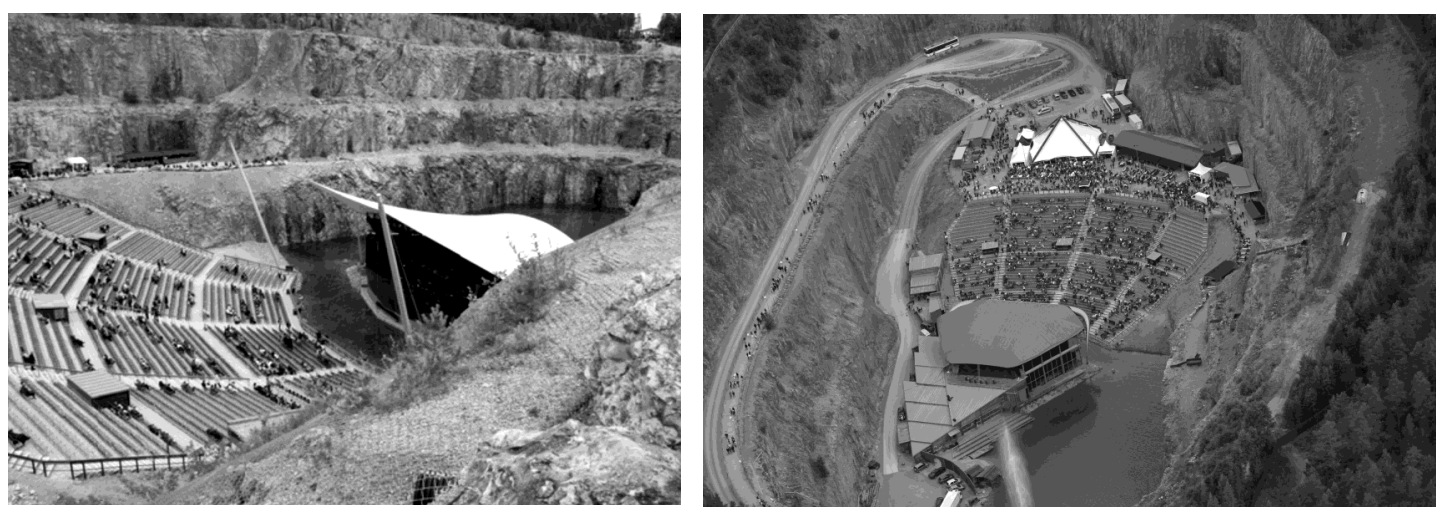

Fig. 14 Granite quarry converted into an auditorium (Rättvik, Sweden). The high rock walls - almost vertical, provide exceptional acoustics on stage, comparable to the most famous amphitheaters of ancient Greece and Italy Source: Photo Calle Eklund.

From a modern perspective, a considerable number of mining areas re-qualification projects that consider environmental, social visual, heritage and economic aspects have been developed. They are examples of approaches to mines and quarries landscapes which show the importance of discovering the opportunity in the alteration (Fig. 11-14).

In the extraction of ornamental rock there are examples of high scenic value areas as the marble quarries of Carrara
(Italy), Iberia (Portugal), Vermont (USA) or cream marble quarries in Monte Coto (Alicante, Spain) which are an example of uniqueness in the shaping of a new landscape, Fig. 11. The recognition of geological landscape aesthetics, desert environments, as well as its operation and ecology can be suggestions for the re-qualification of a space subject to the extraction of materials, Fig. 12. 


\section{CASE STUDY: STUDY OF LANDSCAPE INTEGRATION OF MARBLE QUARRIES CREMA MARFIL DEL MONTE COTO (PINOSO ALICANTE)}

\section{Location and background}

Monte Coto is the most important marble producer and processor hub in Spain and one of the most important worldwide. It accounts for more than half of the Spanish marble exports and - with a total production of over $300,000 \mathrm{~m} 3$ of block and estimated reserves of 8 to $10 \mathrm{mil}-$ lion cubic meters, it is considered the largest marble exploitation in Europe.

Marble extraction began over 70 years ago in a series of irregular plots in terms of size and shape, leased by Pinoso City Council to different companies. At present, the main extraction area occupies more than 250 ha, with around 20 active mining authorizations whose ownership is held by 12 different companies (Fig. 15).

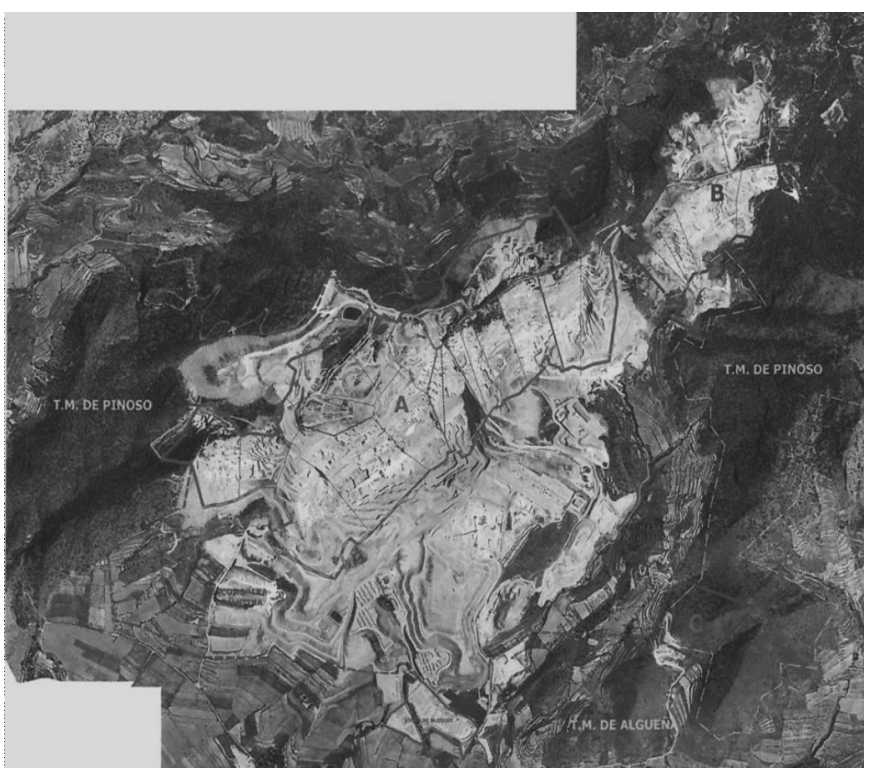

Fig. 15 Mining operation scope

Source: Alba Ingenieros Consultores, S.L.

Mining is carried out on the southern slope of Monte Coto, which forms a foothill oriented northeast-southwest in Sierra del Reclot. The quarries are in the municipality of Pinoso, though far from the town center and visually isolated therefrom. The main storage area is in waste rock grounds in Algueña, just $2 \mathrm{~km}$. away from the town center. Between this town and the main extraction area there is no physiographical barrier whatsoever.

\section{Defining the scope of study and visual analysis}

As a beginning of the landscape integration process the visual impact of the action in the territory was determined through fieldwork and cartographic analysis of the viewshed. A series of field tours were conducted to collect images of the mining activity itself; and from roads, lookouts and main observation points.

The analysis of images collected allows to properly contextualize the activity in the landscape and establish the reciprocal relationship between views from action and views towards action. The views from main observation points were the basis on which visual simulation works were subsequently carried out (Fig. 16).

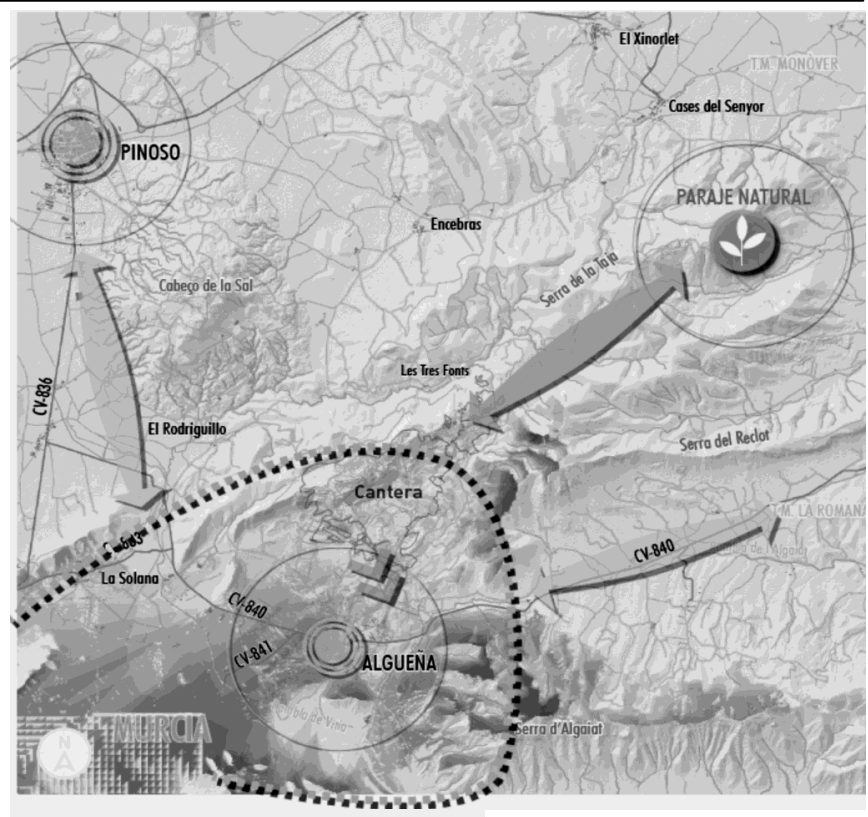

CUENCA VISUAL DESDE LA CANTERA

BAA

ALTA

Fig. 16 Viewshed from the main quarries concentration hub Source: CERCLE \& Alba. Technical documentation.

To select the study area the following factors were taken into account:

1. Functional relationship with the towns of Pinoso and Algueña, the most important urban nodes in the area.

2. Functional, hydrological and visual relationship with Algueña Valley. The proximity of the town of Algueña makes it directly affected by the mining activity. Likewise, the visual condition of the quarry turns to this vineyard valley. The drainage network of Monte Coto slopes of Monte Coto faces Algueña Valley.

3. Formal and ecological relationship with Sierra del Reclot and the Municipal Natural Park of Monte Coto.

Characterization of the landscape

A thorough knowledge of the landscape nature is the basis of any landscape study. To this end a series of works focusing the following key aspects was carried out:

A. Landscape evolution. A search for historic photograph of Monte Coto was carried out, selecting those images depicting the quarries at different operation times, an analysis of aerial photography between 1956 and 2012 and of mapping of land uses at CORINE to determine the territorial evolution of quarries traces, and the collection and analysis of plans and projects underway in Pinoso and Algueña municipalities.

The aim was to determine the features that have remained unchanged over time within the scope of the quarries condition, identify changes in landscape over time, and the possible future scenario (Fig. 17).

B. Landscape organization. Formal structure and soil cover involved in the quarries were analyzed to recognize the general organization patterns of the territorial mosaic in the surroundings of the action and determine different landscape patterns and visual structures. To do this, digital models and cartography of slopes, geology, lithology, industrial uses, physiography, risks, agrological capacity and drainage network was made; and land uses, crops, forest ecosystems and fire danger in relation to soil cover (Fig. 18). 


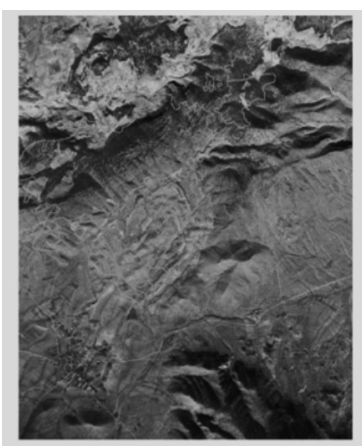

1956-1957

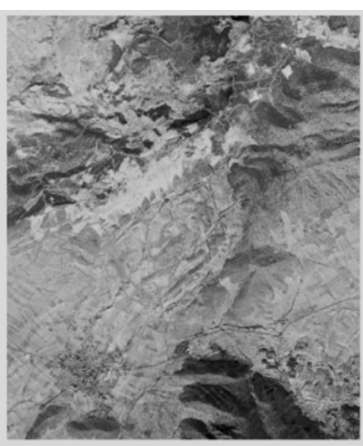

1980-1987

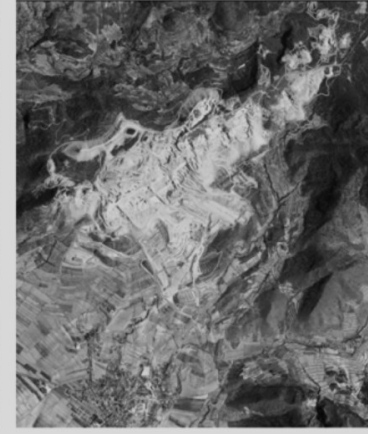

Ortophoto 2002

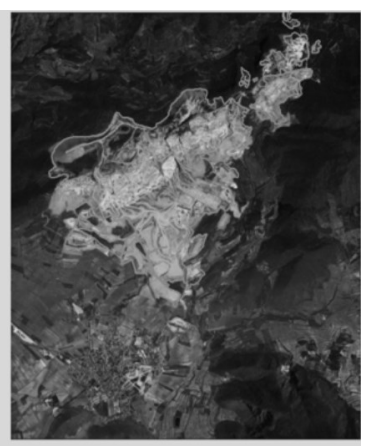

Ortophoto 2012

Fig. 17 Analysis of historical orthophotos to determine the progress of the traces left by marble operations Source: CERCLE \& Alba. Technical documentation.

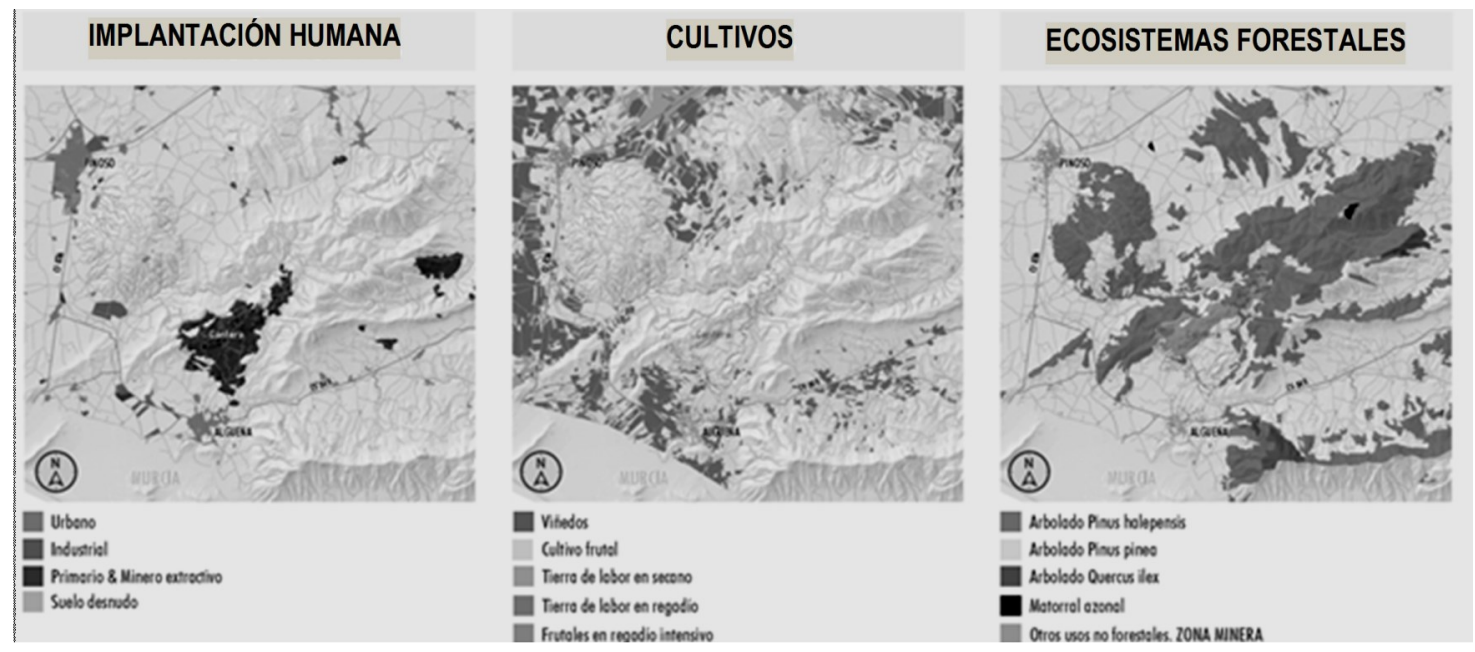

Fig. 18 From the analysis of land cover patterns, borders and structures that allow clarify guidelines for developing an integration strategy that considers the pre-existing conditions and changes in the landscape are detected Source: CERCLE \& Alba. Technical documentation.

C. Landscape units. Landscape units are areas of the territory that have a distinct landscape nature. The evolution a territory experiences by natural or human factors and major components that define its content, are hallmarks of a landscape unit.

A total of 12 landscape units were defined and mapped, defined in terms of territory visual structure, intervisibility and landscape environments existing in the area (agriculture, agroforestry, forestry and mining) (Fig. 19).

D. Landscape resources and conflicts. Within the study area, existing landscape resources of environmental, cultural, visual and social interest will be identified, and aspects that are causing a landscape degradation in the surroundings of the action (conflicts associated to quarries). In parallel, a public participation process in both municipalities was developed (Algueña and Pinos) to hear the views and concerns of all agents affected by the activity.

In addition to the mapping resulting from conflicts and resources, a visuality analysis was carried out, which allows analytical interweaving between visual studies resulting from the cartographic analysis and public participation experiences, Fig. 20. The visuality study proves the recurrent ways of geographical area perception by people. Most valued landscapes, milestones and relevant pathways are indicated, as well as conflicts that were considered as landscape devaluing aspects during the public consultation.

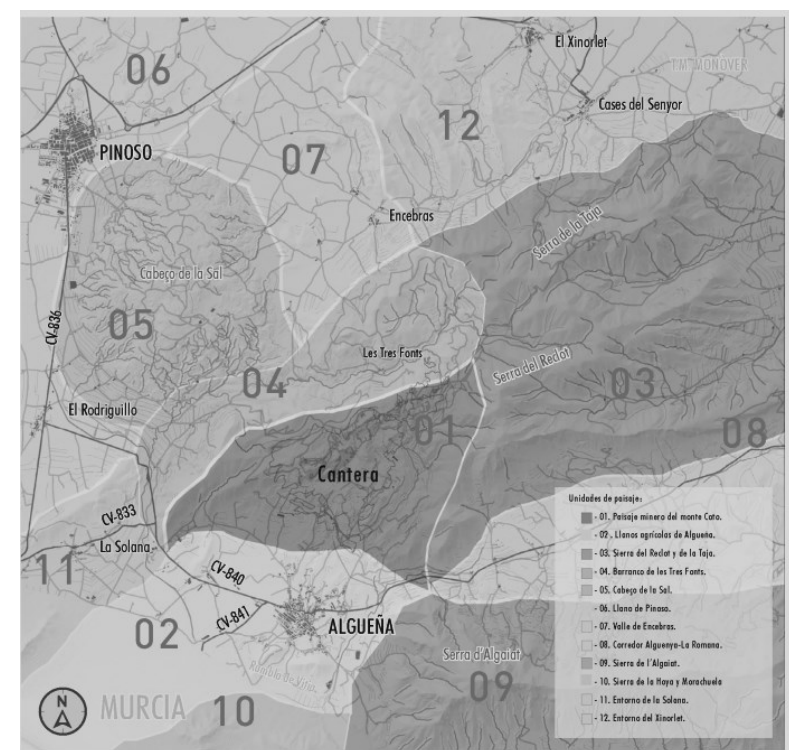

Fig. 19 Landscape units in the surroundings of Monte Coto quarries in Pinoso (Alicante, Spain)

Source: CERCLE \& Alba. Technical documentation.

\section{Area of action. Topography}

A detailed analysis of the particular area of operations concentration was carried out through the exploration of the environmental characteristics closest to the action and a detailed study of morphology adaptation possibilities. 
In this phase of the study we analyzed different aspects such as relief and slopes, water mains, orientation, human settlement, agricultural and forestry systems and visual display, and edges of the mining site and landscape force lines were cartographically determined (Fig. 21).

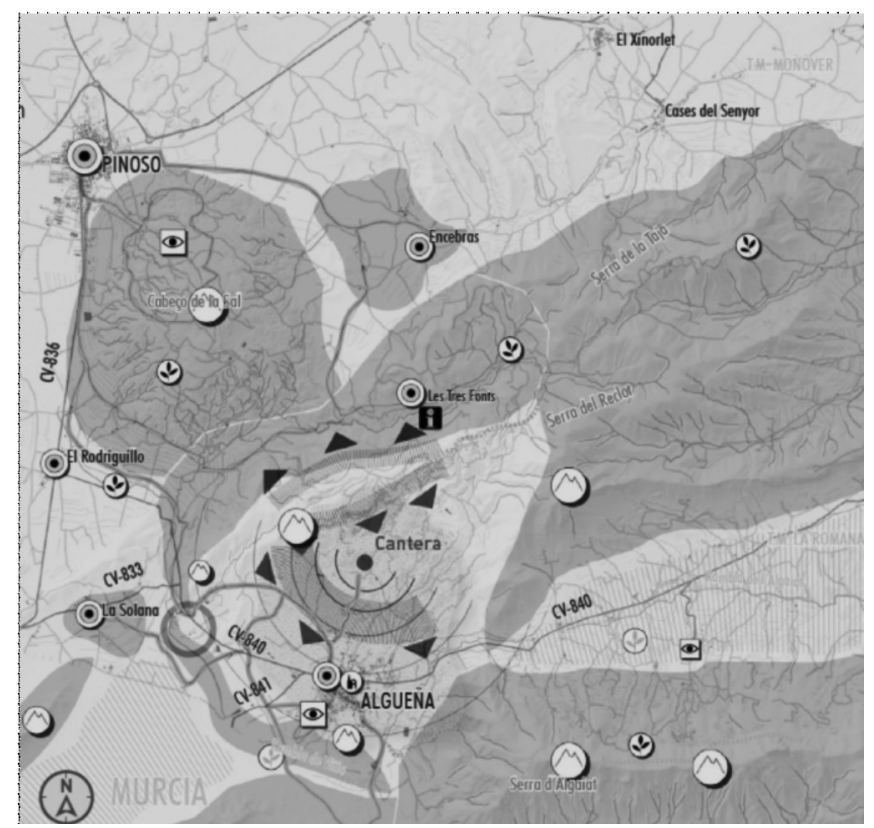

Valuation of landscape integration and integration measures

To assess the landscape integration of mining activity in Monte Coto, impact caused by quarries to the landscape structure of the territory was studied and the following aspects were particularly studied:

1. The relationship of the action with environmental landscape resources of cultural or visual interest.

2. The way in which the intervention alters or adapts to landscape organization.

3. The possible alteration of main components of the landscape (vegetation and hydrological systems).

4. The impact on areas of particularly fragile territory with low activity adaptation rates.

Taking as final situation that defined by the different projects that operators are planning to develop in the medium term, an assessment of the activity visual integration was carried out from a series of topographic profiles drawn from the main observation points, which reflected the before and after, and simulations of the evolution of the main expected extraction and storage structures (Fig. 22 and 23).

As a conclusion of the study, a number of measures to integrate mitigation or corrective nature were defined, aimed at correcting certain aspects of the projected mining operation to achieve a better landscape integration.

Fig. 20 Visuality map of Coto Pinoso quarries

Source: CERCLE \& Alba. Technical documentation.

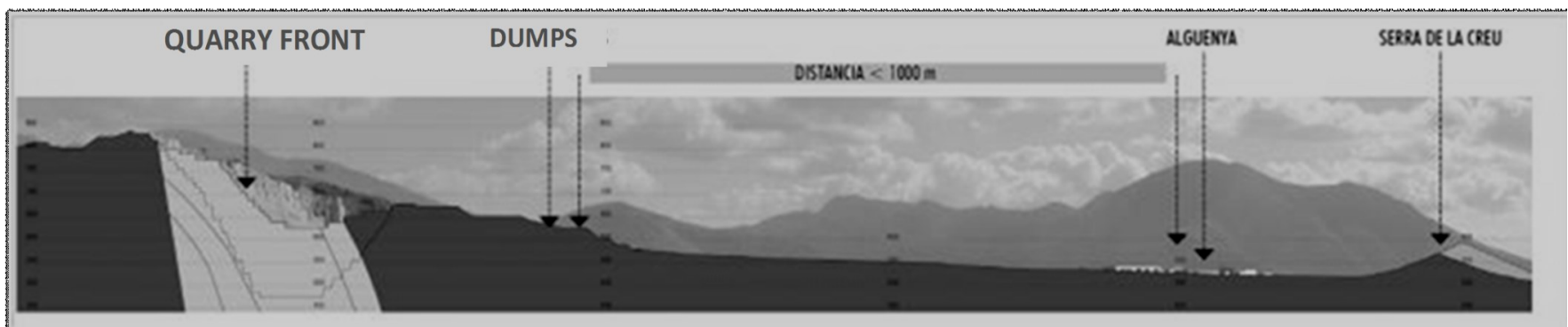

Fig. 21 Topographic profile of the operations area

Source: CERCLE \& Alba Consultores, S.L. Technical documentation.

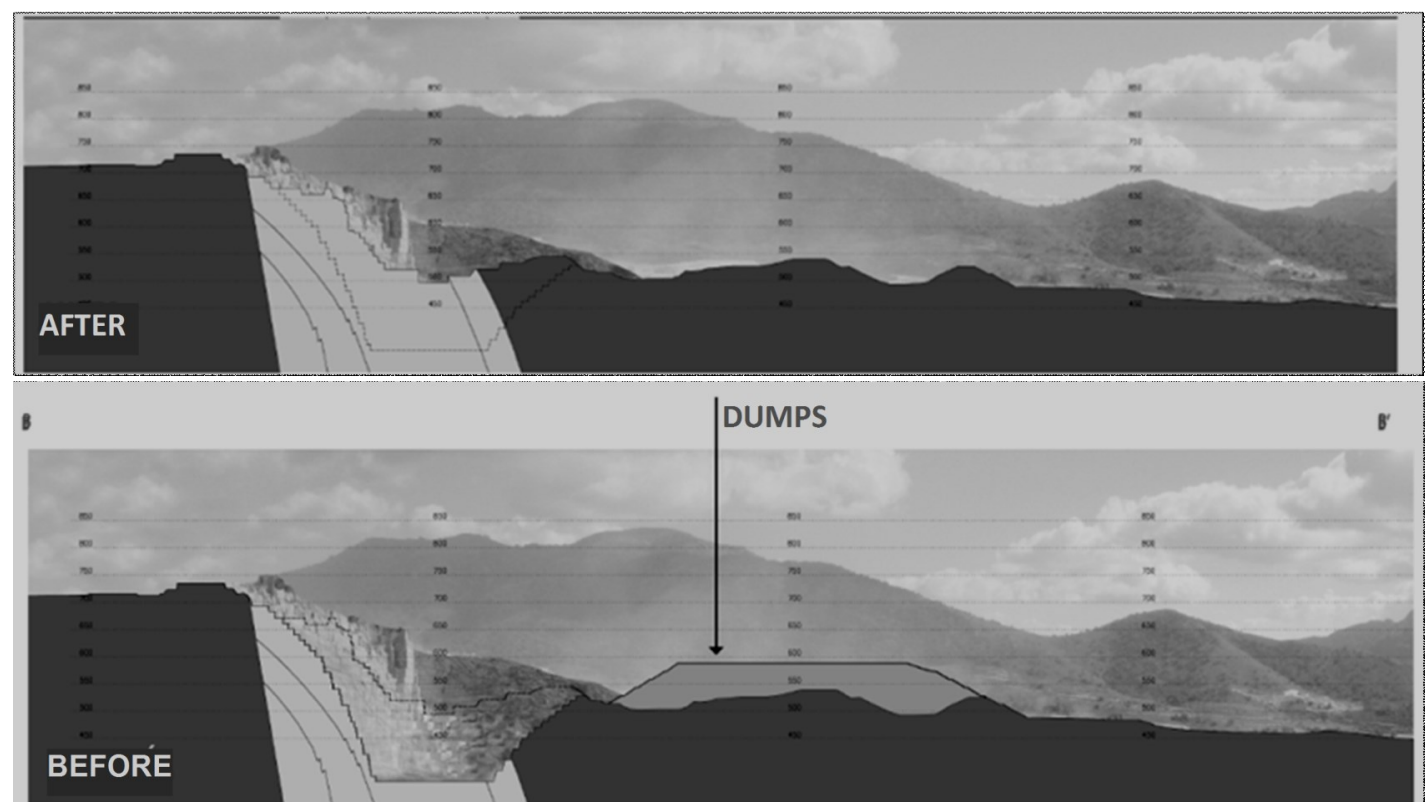

Fig. 22 Superposed visual profiles carried out for the assessment of mining activity landscape integration in Monte Coto Source: CERCLE \& Alba Consultores, S.L. Technical documentation. 

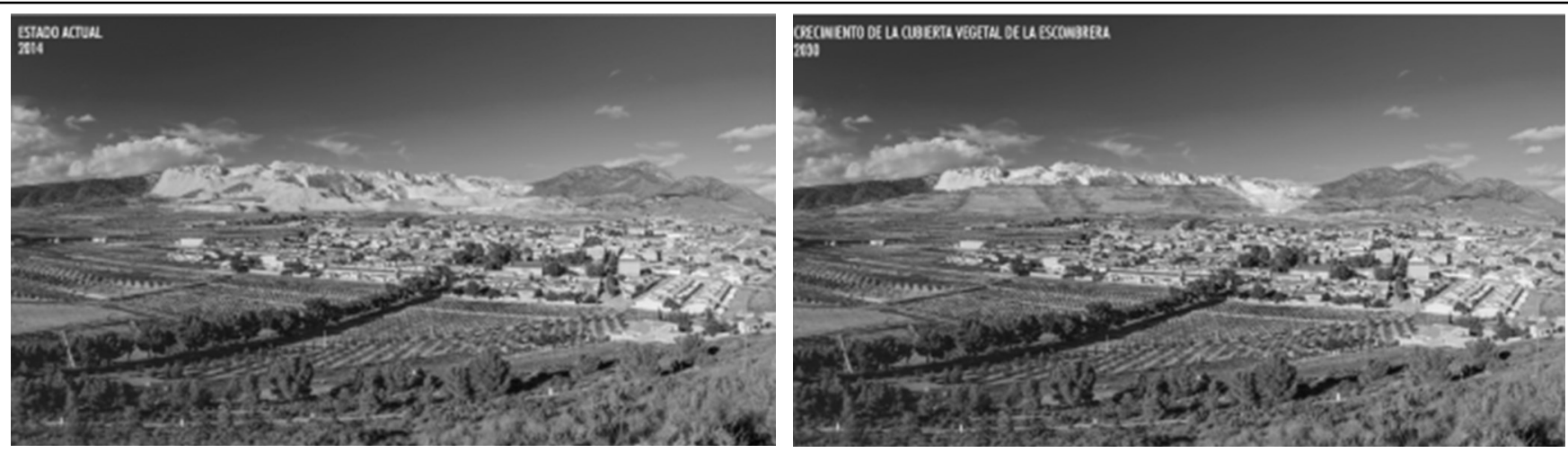

Fig. 23 Simulation of the possible landscape evolution at Pinoso marble quarries (Alicante). To do this, two-dimensional computer graphics from an image taken from one of the observation points defined as major in the visual analysis have been used Source: CERCLE \& Alba Consultores, S.L. Technical documentation .

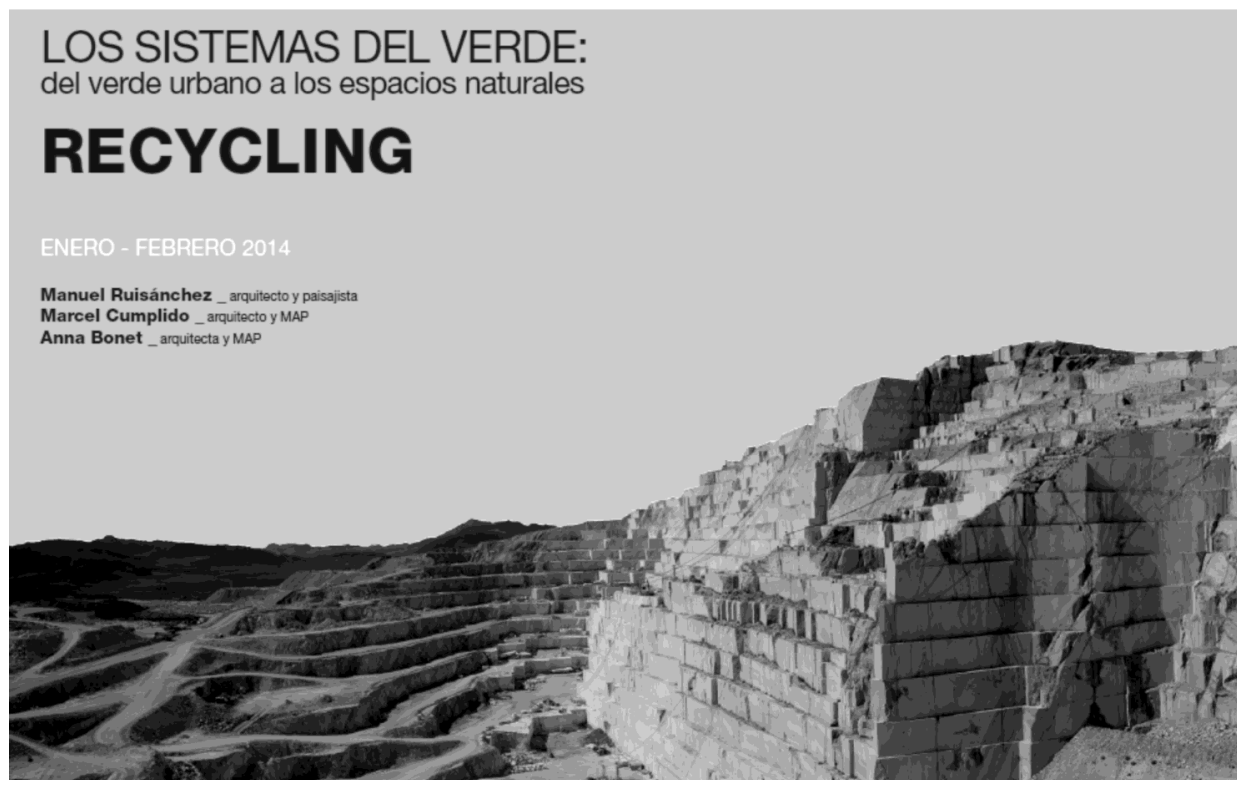

Fig. 24 Experimental workshop on alternative futures for Coto Pinoso quarries, carried out in 2014 Source: CERCLE.

The main measures proposed were:

1. Revegetation of dumps. Covering of dump surfaces with a forest system acting as connector between El Puntal and Penya de la Campana, the two nearest main reliefs which currently keep a well preserved forest type plant cover.

2. Reinstatement of implementation areas and roads through the execution of rehabilitation measures foreseen in the projects, and reinstatement of forest agricultural roads to reproduce the patterns of the traditional agricultural landscape of affected area.

3. Integration of dumps according to the scale of the place, promoting a physical and visual transition with agroforestry mosaic landscapes. In this regard, the topography design is an essential aspect in the mining and landscape harmonization process.

4. Development of a public use that allows the valuation of a unique landscape as marble quarry land cuts, comparable to international recognition quarries as Carrara in Italy, Vermont in USA or Iberia in Portugal.

5. Development of a management plan for the mining environment in Pinoso and Alguenya as main economic activity in this territory. This plan is considered key to a better exploitation of mineral resources, better mana- gement of industrial uses associated to mining and better regulation of tailings provision.

\section{Experimental workshop on alternative futures of Coto Pinoso quarries}

In 2014 an experimental workshop on alternative Coto Pinoso quarries futures called "Green Systems: from urban green to natural aspects" was carried out. "Recycling"with the students of the Landscape Architecture Master at the School of Architecture of Barcelona, coordinated by Manuel Ruisánchez, Marcel Cumplido and Anna Bonet.

In this workshop students were proposed to explore the possibilities and opportunities offered by the unique landscape emerged from marble operations at Monte Coto, and propose ways of value increase and future development.

The varied and imaginative solutions developed by students made it clear - regardless of the negative environmental effects the operation has objectively caused in the natural environment, the impressive potential of the landscape emerged from marble quarries, and that far from considering it a degraded space, they have aesthetic and cultural values that can be used for multiple purposes. Some of the proposals developed by students are included in the figures below (Fig. 24 and 25). 

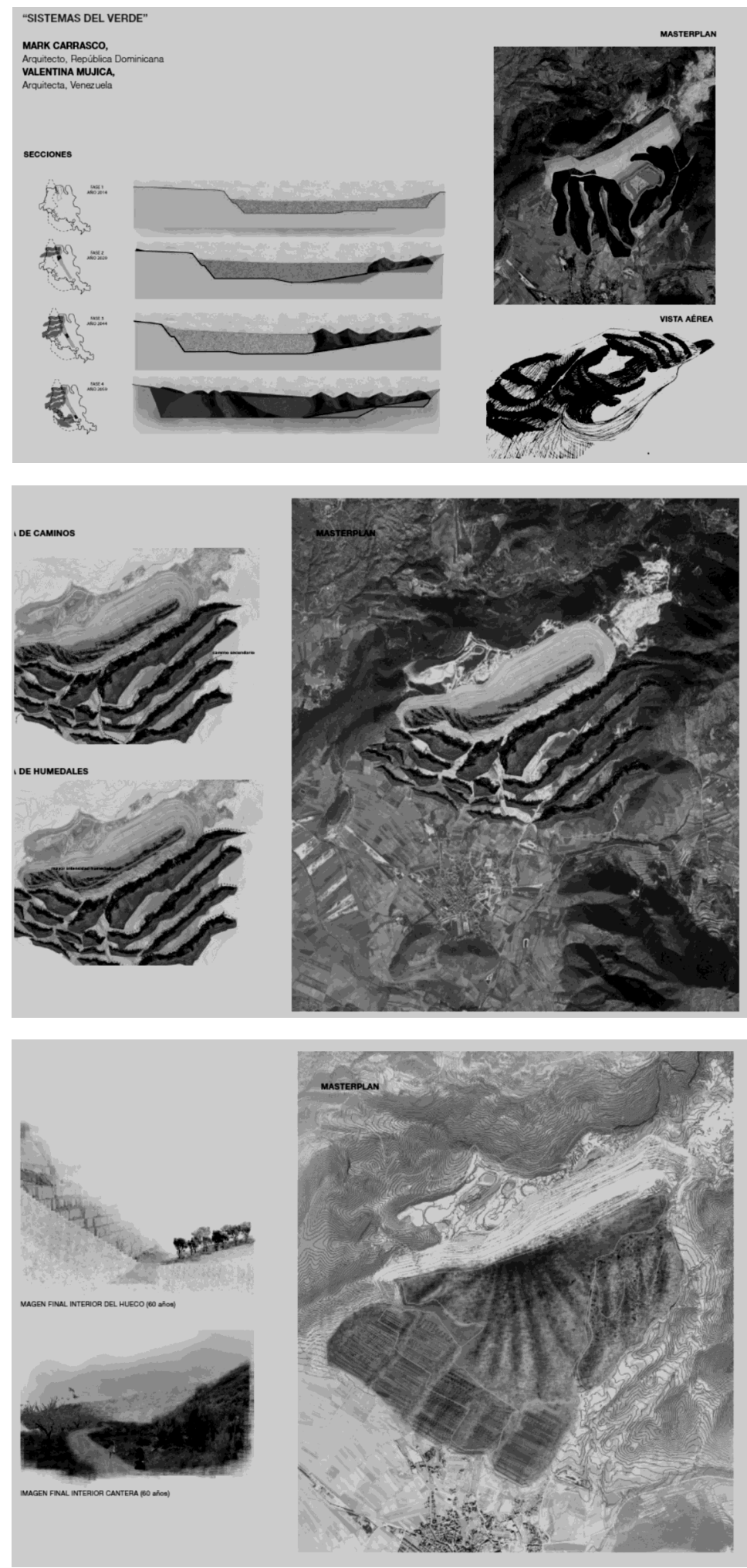

Fig. 25 Some of the proposals made by the students of the Landscape Architecture Master at the School of Architecture of Barcelona on alternative futures for Monte Coto

Source: CERCLE.

\section{SUMMARY AND CONCLUSION}

According to Martínez de Pisón [3], landscape is the result of historical experience and can tell landscape-image from landscape-territory. The landscape-territory emerges as geographical shape and object, accumulating territorial history, and landscape-image as a created image, reservoir of looks over time, sum of experiences, practices, studies, thought, identities and art. "Visuality" of a place is the landscape-image and its territorial materialization.
From this perspective, landscape integration means all actions that aim to ensure the implementation of a project or proposal with the environment where it is located in a consistent manner. It is an implementation process of a new activity in the territory that assumes landscape as an argument, suggestion and conditioning at all times, looking for the slightest alteration of the characteristic features of the place. 
At the sudden transformation of the territory, it is necessary to study possible ways for receptiveness of the change in the landscape and ecological mosaic regeneration. In short, re-qualification of the altered space. This increase in value can be of environmental, cultural, socialvisual and even economic nature, through the implementation of new activities.

Very often, the issue of landscape integration comes down to the idea of visibility, but landscape requires more than a mere spectator perspective. Instead of landscape visibility, the concept of "visuality" characterizes a landscape, a displayed territory, the spatial relationships that occur more frequently between a community and its environment.

Visuality analysis of a landscape can provide conclusions about the path to follow when dealing with a mining site integrating-regenerating action. Two ways to face the intervention to increase landscape value can be set in principle, among which there are plenty of intermediate situations.

The two ways of approaching the problem can be summarized as "heal the wound" or "assume the wound and emphasize its value." These two trends lead to ways to undertake the project, involving different strategies, Fig. 7.

The gesture of rehabilitating a space in order to "heal the scar" leads to acceptance of that landscape as a place devalued after the alteration and therefore re-qualification is conducted through mechanisms of concealment, mimicry, assimilation of the environment or re-naturalization processes. This is the busiest path in the integration of mines and quarries due to the dispersion of this activity in the territory, in places where "visuality" displays perceptive gaps, hidden spaces not learnt by the community.

On the opposite pole of this conception, the way of acting on the landscape is "assuming the scar" generated by the activity as a cultural trail of a community, sometimes mandatory due to impossibility to return to point 0 , other times becoming an opportunity for the re-qualification of a place.
In this sense, the integration of public use in old quarry promotes apprehension about "the wound" and generates new uses. These dynamics cause a "visuality" on these spaces which assumes contemporary aesthetic categories, assuming the current mixing of landscapes. Given the new unprecedented scenarios created, original project answers are emerging that provide another perspective on the problem and similarly there are experiences that show how to capture the opportunity in devastation.

Between closing the wound or assuming the scar as part of the landscape, a range of possibilities that must be explored in order to find those strategies that improve cultural, social, economic, environmental and visual conditions appear. Integration, imitation, concealment, fusion, contextualization, harrmonization, singularization, positive "visuality" and recycling, are some basic strategies that can be assumed and, where the complexity of the project requires it, can be simultaneously implemented in a landscape integration process.

In this context, the case study of Coto Pinoso marble quarries (Alicante, España) illustrates the methodology and objectives of the landscape integration. The marble exploitation of Coto Pinoso are considered the largest ornamental rock quarry of Europe, has a high impact on the landscape and pose a challenge for the future of this territory. But, they are an example of uniqueness in shaping a new landscape of high scenic value.

\section{REFERENCES}

[1] Díez Torrijos, C. López Jimeno and C. Mataix González. Manual de Integración Paisajística de Minas y Canteras, unpulished.

[2] Guía metodológica. Estudios de Paisaje, Generalitat Valenciana, Consejería de Infraestructuras, Territorio y Medio Ambiente, 2011.

[3] E. Martínez de Pisón. „La experiencia del paisaje”, in Retorno al Paisaje, J. Mateu Bellés and M. Nieto Salvatierra, Evaluación de Recursos Naturales S.A., 2008.

\author{
Carlos López Jimeno \\ Escuela Técnica Superior De Ingenieros De Minas. UPM. \\ c/Ríos Rosas 21, 28003 Madrid, SPAIN \\ e-mail: carlos.lopez@madrid.org \\ Ignacio Díez Torrijos \\ CERCLE Territorio, Paisaje y Arquitectura. \\ C/Caballeros, 26, 46001 Valencia, SPAIN \\ e-mail: nacho@cercle.es \\ Carmen Mataix González \\ ALBA Ingenieros Consultores, S.L. \\ C/Lagasca, 95 - Local CN Lagasca, 28006 Madrid, SPAIN \\ e-mail: cmataix@albaingenieros.com
}

